\title{
Methods of temperature measurement in a radio-acoustic tropospheric sounder
}

\author{
G. Boxixo $(*)-$ P. P. Lombardini $(* *)-$ P. Trivero $\left({ }^{*}\right)$
}

Received on November 8 th, 1976

\begin{abstract}
SUMMary. - The temperature of the lower troposphere is inferred by measuring with a doppler radar the speed of a powerful acoustic wave, capable of periodically perturbing the index of refraction of air. Three methods for performing these measurements are described.

Riassusto. - La temperatura della bassa troposfera viene dedotta da misure della velocita del suono ottenute a nezzo di un radar doppler, utilizzando la perturbazione periodiea dellindice di rifrazione dellaria, provocata da una potente onda acustica. Vengono deseritti tre metodi per ottenere tali misure.
\end{abstract}

\section{INTRODLCTION}

A radio-acoustic sounder of the rertical temperature distribution in the lower troposphere, inspired by the Stanford RASS $(2,5)$, is in a stage of construction in the premises of the Laboratorio di Ricerche Ambientali dell'Ente Nazionale per l'Energia Elettrica (ENEL) at Trino Vercellese $\left(^{3}\right)$.

As it is well known, the system consists, in its essence, of a powerful acoustic generator beaming toward the zenith a short train of

$\left.{ }^{*}\right)$ Istituto di Fisiea Generale deil'lniversita, Torino.

(**) Laboratorio di Cosmo-geofisiea del Consiglio Narionale delle Rieerehe, Corso Finme 4, Torino. 
sinusoidal waves. The local speed of this signal during its rise is controlled by the square root of the air temperature. This speed is continuously monitored from the ground by means of a doppler madar. The echo is due to the change in the refraction index of air caused by the intense pressure of the acoustic wave. The record of the measured sound speed as a function of delay allows the rlirect plotting of the temperature rertical profile.

In our knowledge, this is the first attempt to build a radio-acoustic sounder after the Stanford experiment. In our design we have made an effort to minimize dimensions and improve mobility of the RASS system. For this purpose, we have adopted a cloppler radar having carrier frequency in the $159 \mathrm{MHz}$ band, to which corresponds an acoustic Bragg resonance of circa $360 \mathrm{~Hz}$. Consequently, the areas of both acoustic and radar antemnas are reduced compared with the Stanford RASS. Obriously, since the acoustic atmospheric absorption is about tenfold higher at $360 \mathrm{~Hz}$ than at $85 \mathrm{~Hz}$, which is the sound frequency used at Stanford, a reduction in thermal sounding range might be expecter. However, it is easy to realize that atmospheric absorption brings a negligible contribution to the attenuation loss at heights below $2 \mathrm{~km}$, with respect to the inverse of the squared clistance term. Hence, we do not foresee any sizable sounder range reduction as an eflect of the increased sound frequency. Besides, we hope to operate in a more favorable region of the atmospheric turbulence spectrum.

\section{General seting}

Fig. 1 shows a general view of the installation at Trino Vercellese. The photo was taken from the top of the meteorological tower, which is $120 \mathrm{mt}$. heigh.

On the roof of the central building one may spot the first installed acoustic cell, a $\sim 2 \cdot 2 \mathrm{mt}^{2}$ brick square. The complete acoustic array will include 9 of these cells, with an expected yield of the order of 100 acoustic watts.

The transmitting and receiving antennas of the bistatic cloppler radar will be located at the lower left and upper right corners, respectively, of the fenced ground shown in the picture. The shielding eflect of the interposed building should hopefully reduce mutual interference between the two antennas. The antenna spacing has been set to leave 
METIODS OF LEMPERATURE HEASUREMENT IX A RADIO-ACOLSTIC ETC. 239

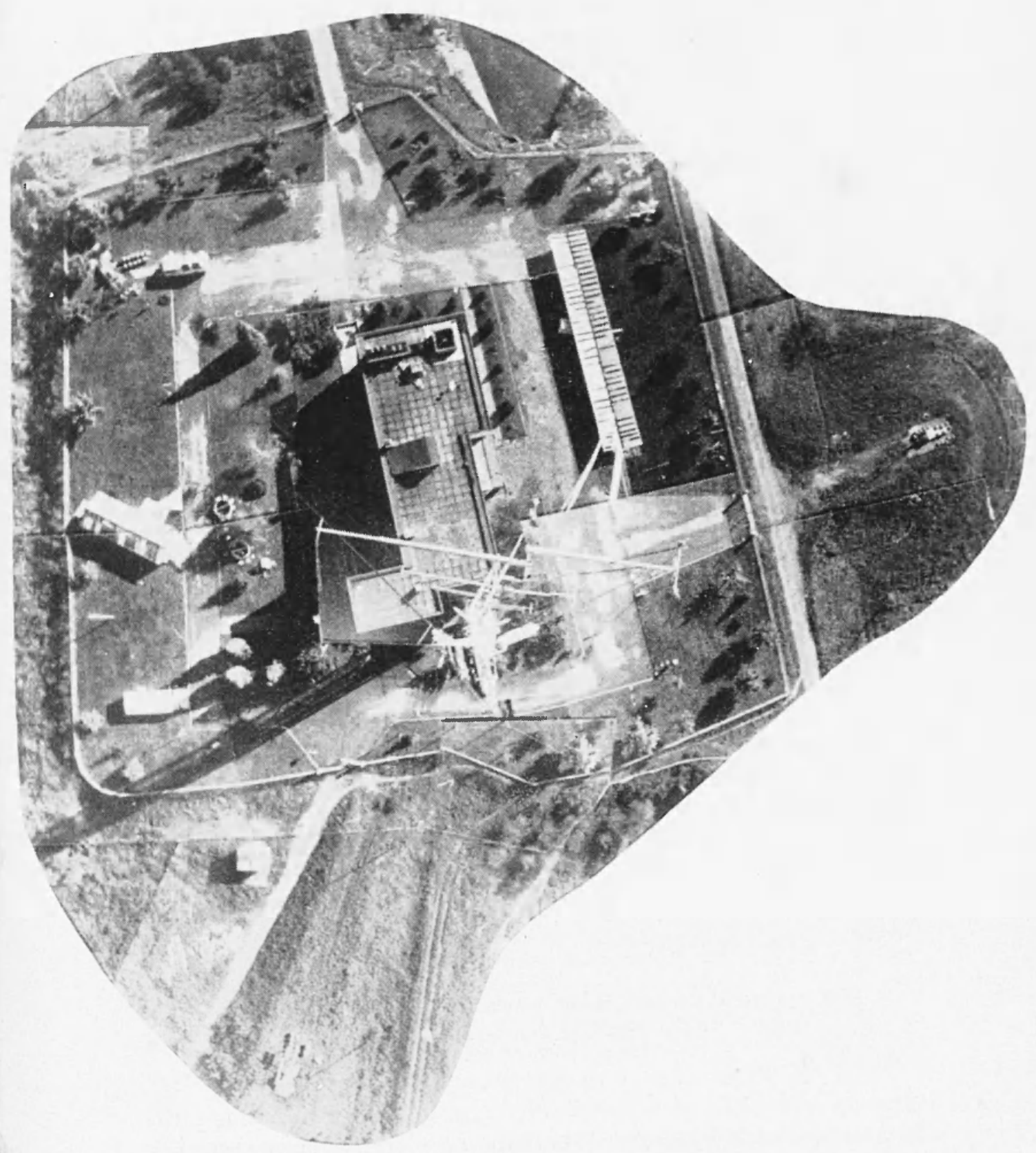

Fix. 1 - General view of the installation site, at 'Trino Vercellese. 
the top of the tower ont of the main radiation lobes, although sounlings above $150 \mathrm{mt}$ are possible. Square arrays composed of 4 irlentical one-director Yagis will be installer.

\section{RADAR EXPERIMENTS}

The radar system utilizes a standard quartz-controlled commmication transmitter which can yield a maximum of 10 watts C.W. The insirlious 7 th harmonic ripple of the $50 \mathrm{~Hz}$ power line was eliminaterl from the carrier by carefully stabilizing the transmitter power supply $\left({ }^{1}\right)$.

The antodyne receiver, which includes a $\mathrm{RF}$ amplifier, a doublebalanced mixer, and a high-gain, Li amplifier with a $335-370 \mathrm{~Hz}$ pass-band filter, was assembled in the laboratory.

We have tested the rarlar system on the ground, using as scatterer a dipole interrupter 360 times per second by means of a reed switch. Clearly, such a dipole, by changing drastically its cross-section at the rate of the doppler frequency expected in the operating sounder, offers sidebands which perfectly fit the receiver. The scattered signal is maximized when the distance between dipole and antennas is an integer number of half-wavelengths.

In this way we were able to optimize the amount of injecter LO signal, directionally deriver from the transmitter. The interrupted dipole was received within a horizontal distance of about $1.5 \mathrm{Km}$. Taking into account the high level of man-made interference present, and the fact that the two-way raypath was tangent to wind-stirred vegetation, we estimate this result to be highly promising.

\section{METIODS OF MEASUREMENT}

The temperature-measuring procedure of our system is still in a design stage. Three different methork of measurement have been consirlered:

1) - In methor 1, sketcherl in Fig. 2, a rlelayed gate chooses the sounding height, where the counting of the doppler frequency of the received echo is performed. Such a counting requires a signal-to-noise ratio of $27 \mathrm{db}\left({ }^{3}\right)$ or better. The actual counting 


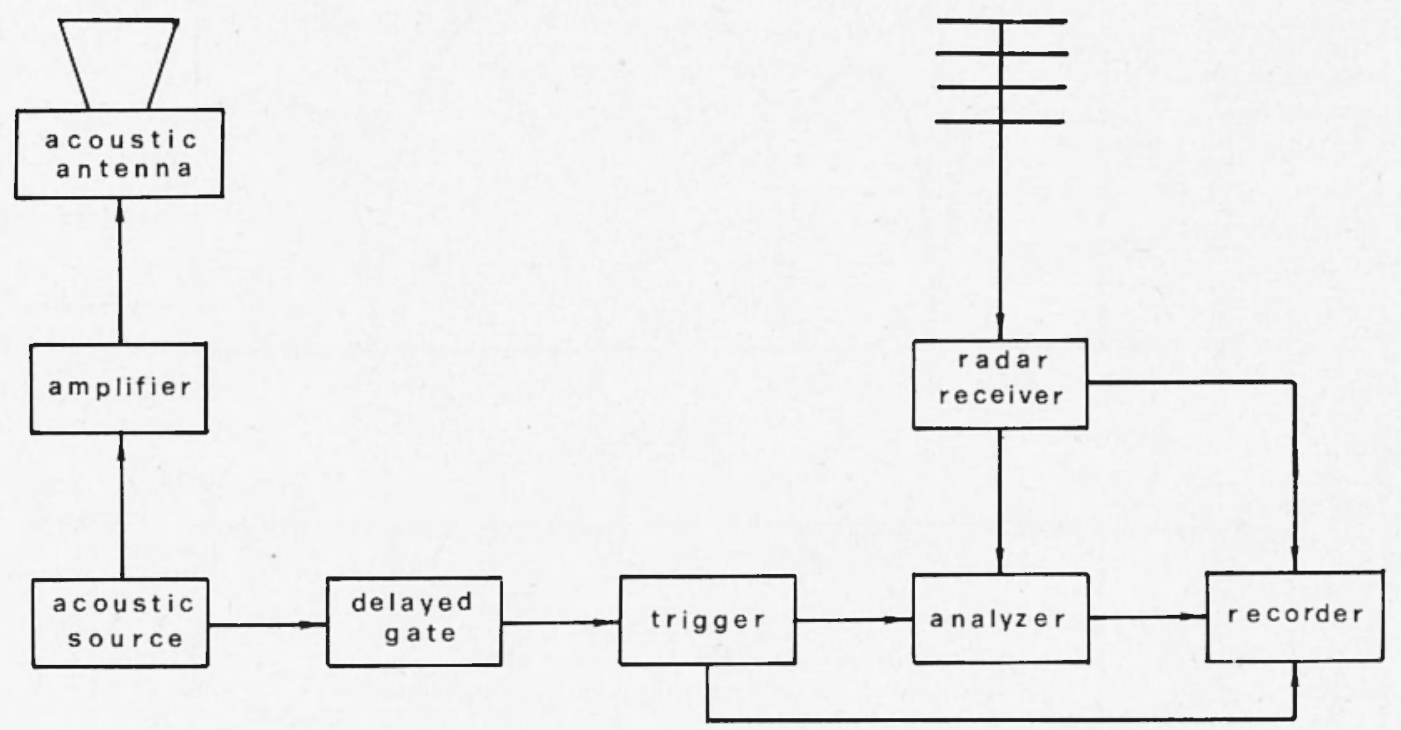

Fig. 2 - Block diagram of Method 1 for the spot measurement of the temperature.

is processed in the Analyzer of Fig. 2, and converted in analogic form. This output, together with the roppler signal, are displayed in a Bryant-Southerns quick-response recorder.

2) - Methorls 2 is based on the Bragg resonance property, for which the RASS echo reaches a maximum when the frequency of the acoustic radiation equates the doppler frequency. The behavior of the echo intensity as a function of the acoustic frequency was studied by Marshall ("), and is plotted in Fig. 3. In the figure, the abscissae are acoustic/doppler frequency ratios, the ordinates are ratios of the echo intensities, in ab. Moving from the top to the bottom of the figure the 3 plots indicate a number of periodicities of the acoustic train of 10,20 and 100 , respectively.

With this method, sketcherl in Fig. 4, the height of operation is selected by a rlelayed gate, as in Method 1. A succession of soundings is then performerl using an acoustic radiation of continuously increasing, or decreasing, frequency. The acoustic frequency and the corresponding echo intensity are both recorder at each sounding. The acoustic frequency at which a maximum of echo intensity occurs is the doppler frequency sought for. 

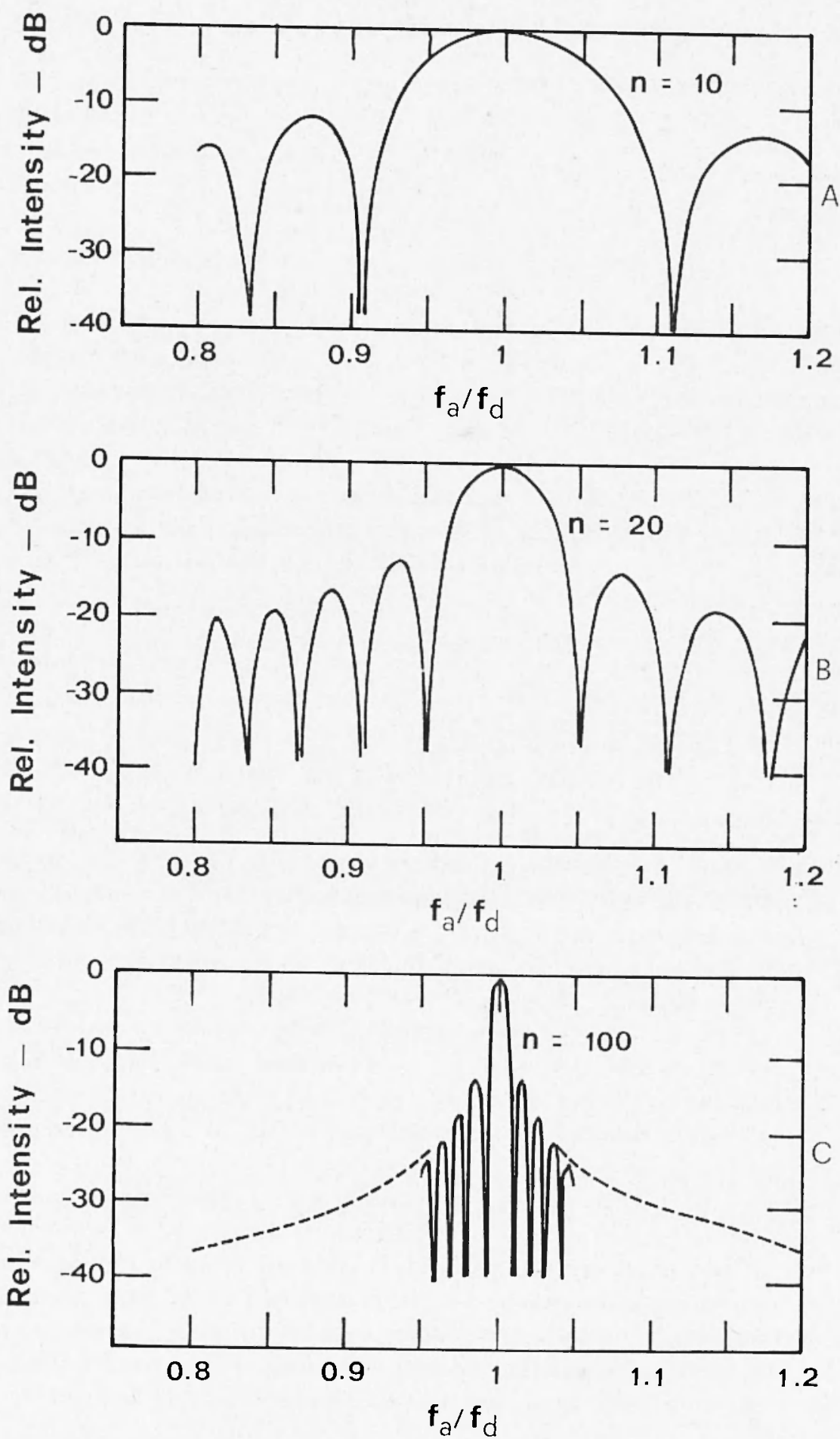

Fig. 3 - The relative echo intensity as a function of the acoustie doppler frequency ratio; $n$, number of periodicities in an acoustic train. 


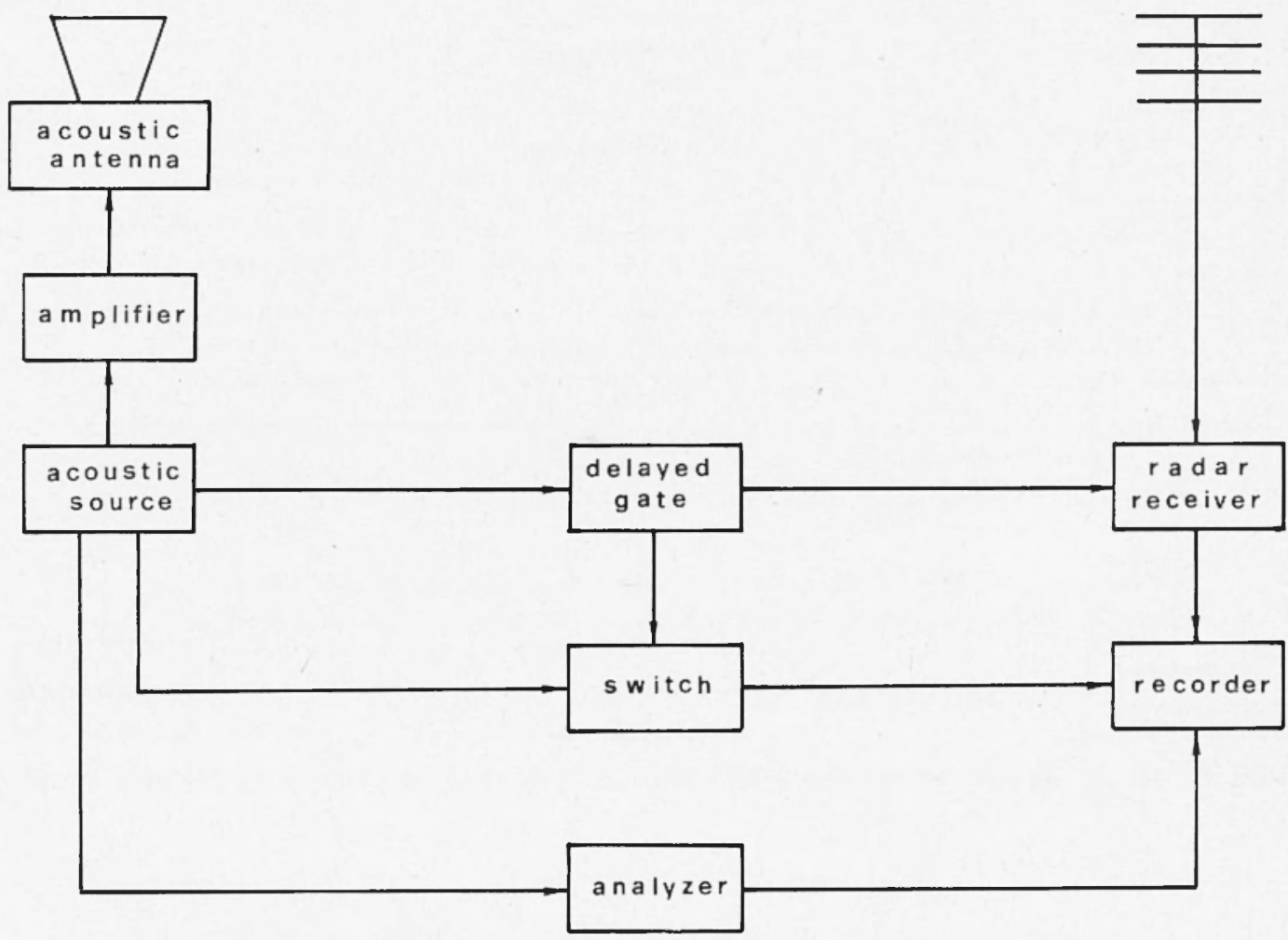

Fig. 4 - Block diagram of ILethod 2 for the spot measurement of the temperature.

Examining the plots of Fig. 3 it may be observed that this method can probably work even when the signal-to-noise ratio is well below $10 \mathrm{rb}$.

3) - Methor 3 (see Fig. 5) is a rather faithful reproduction of the scheme divised by Stanford for the systematic sounding of the vertical temperature profile. Here the delay of the gate increases automatically by preassigned steps of about $10 \mathrm{mt}$ until a height span of circa $1500 \mathrm{mt}$ is miformly covered. This operation is performed in the Amalyzer, which basically consists of a quartzed clock, a counter, and a set of memories. The frequency is measured by counting the number of clock oscillations contained in a griven number of periodicities of the sampled signal. This measurement can be repeated after a pause of 2 clock cycles, 


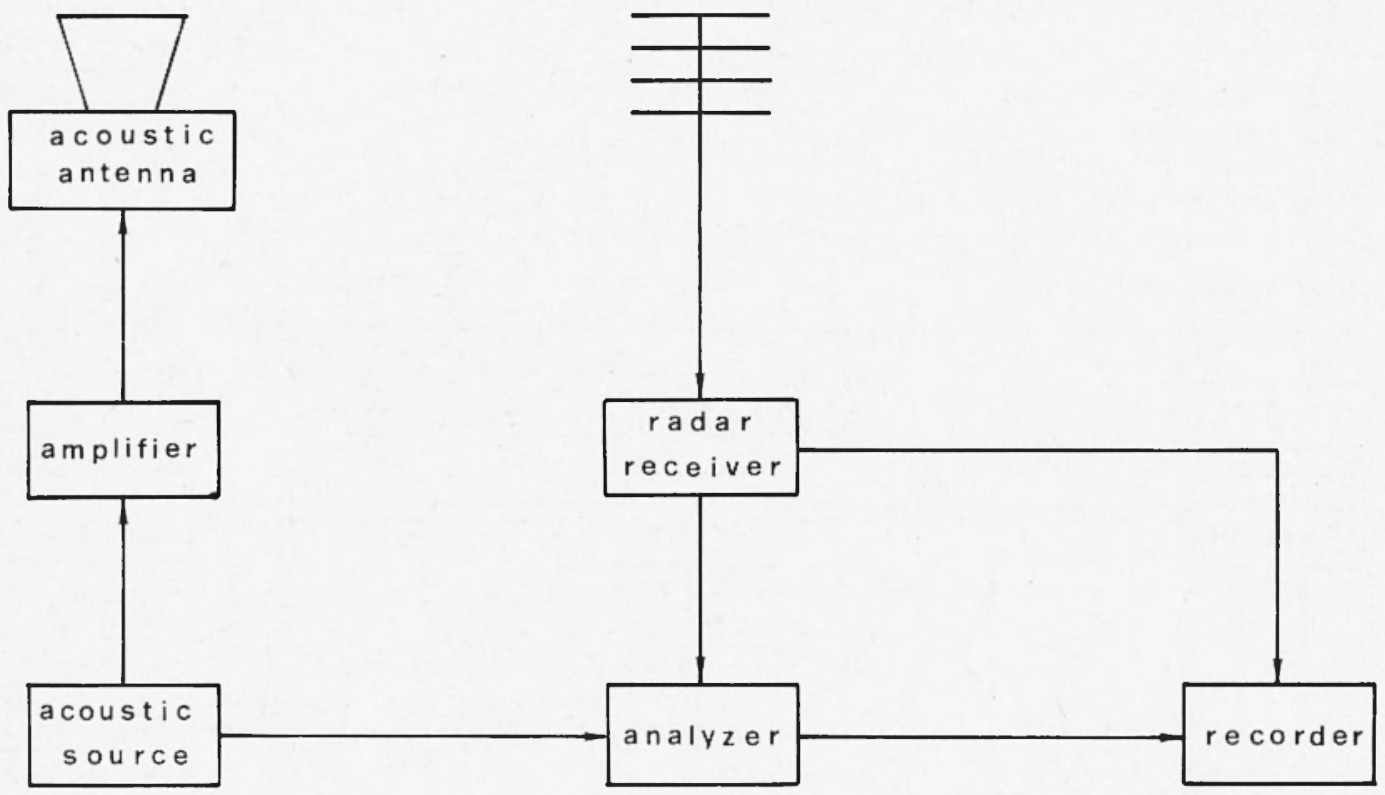

Fig. 5 - Block diagram of Method 3 for the measurement of the vertical temperature profile.

and the number of repetitions may be chosen in binary succession up to 128 times, to which corresponds a height of about $1500 \mathrm{mt}$. Since the rloppler frequency is expecterl to vary by only few $\mathrm{Hz}$ in the height span considererl, the digital-to-analog conversion is limiter to the last 8 bits of the counter output. This allows a better rearling resolution of the vertical thermal profile.

When the radio-acoustic somuler operates at a constant repetition rate, the analyzer memorizes the temperature readings taken at each height, and draws for the recorder the profile of the averages at every 16 somblings. We are planning to make use of all the 3 methorls listerl.

Method 1 seems ideal in the initial arljustment stage. Method 3 was conceived for the systematic acquisition of meteorological data. Finally, methor 2 represents a new approach which offers interesting possibilities, expecially in view of increasing the limit height of thermal sounrling. 
METIODS OF TEMPERATLRE MEASUREMEXT IN A RADIO-ACOUSTIC NTC. 245

\section{REFERENCES}

(1) ACKER A. E., 1975. - Eliminating transmitter clutter in doppler radar systems. "Microwave Journal", 18, November, pp. 47-50.

(2) Fraxket M. S., Petersox A. M., 1976. - Remote temperature in the lower troposphere. "Radio Science", 11, pp. 157-166.

(3) Lombardixi P'. P', Bosiso G., 1975. - Metodo radioacustico per la misura del profilo termico rerticale della bassa troposfera. "Rivista Italiana di Geofisica", 2, pp. 23-26.

(1) Marsitali J. M., 1972. - A radio acoustic sounding system for the remote measurement of atmospheric parameters. "Sci. Rep. No. 39, SU.SEL. 72-003 Stanford Electronics Laboratories", Stanford, California, pl. 152.

(5) Norti E. M., PE'Tersos A. M., PARRY H. J)., 1973. - RASS, a remote sensing system for measuring low-level temperature profiles. "Bull. Amer. Meteor. Soc.". 54, pp. 821-825. 